\title{
Tensile Transformation-Mismatch Plasticity of Bismuth Sesquioxide
}

\author{
David C. Dunand ${ }^{\dagger}$ and Jeffrey L. Grabowski ${ }^{*, *}$ \\ Department of Materials Science and Engineering, Northwestern University, Evanston, Illinois 60208
}

\begin{abstract}
This study reports on experiments where bismuth sesquioxide $\left(\mathrm{Bi}_{2} \mathrm{O}_{3}\right)$ was cycled between its high-temperature $\delta$-phase and one or more of its low-temperature phases $\left(\alpha-, \beta-\right.$, or $\left.\gamma-\mathrm{Bi}_{2} \mathrm{O}_{3}\right)$ while being subjected to uniaxial tensile stresses in the range of 0.11-0.55 MPa. Reproducible strain increments of $0.4 \%-3.9 \%$ have been measured after each thermal cycle, and total tensile fracture strains of $10 \%-28 \%$ have been obtained using a combination of isothermal creep and transformationmismatch plasticity. The strain due to transformation mismatch plasticity has been determined by two different methods and is proportional to the applied stress, which is quantitatively consistent with theoretical predictions for transformation superplasticity.
\end{abstract}

\section{Introduction}

Superplasticity, which is defined as the ability of crystalline materials to deform in tension up to very large strains (typically $>100 \%$ ), can be divided into two categories, based on the deformation mechanisms: microstructural superplasticity and internal-stress superplasticity. ${ }^{1}$ The former type relies on grainboundary sliding at constant temperature and has been reported in ceramics with stable grains less than $\sim 1 \mu \mathrm{m}$ in size. ${ }^{1,2}$ Conversely, internal-stress superplasticity occurs via an accumulation of strain increments during thermal cycling and is independent of grain size. Each strain increment is produced when internal mismatch stresses within the material are relaxed under the effect of an external biasing stress. These internal stresses are produced during a temperature change by a volume mismatch, because of thermal expansion or allotropic transformation between grains in singlephase materials or between phases in composites. Although many metals, alloys, and metal-matrix composites have been reported to deform by internal-stress superplasticity when subjected to thermal cycling, ${ }^{1,3,4}$ this phenomenon has not been demonstrated yet for ceramics.

Among allotropic ceramics, one of the best candidates for transformation-mismatch superplasticity is bismuth sesquioxide $\left(\mathrm{Bi}_{2} \mathrm{O}_{3}\right)$, because of its low transformation temperature of $730^{\circ} \mathrm{C}$ (which is high in comparison to its melting temperature, $824^{\circ} \mathrm{C}^{5}$ ), the large allotropic volume mismatch of $6.9 \%$ between its lowtemperature $\alpha$-phase and its high-temperature $\delta$-phase, ${ }^{6}$ and the high creep ductility of the $\delta-\mathrm{Bi}_{2} \mathrm{O}_{3}$ phase. ${ }^{7,8}$ Early experiments indeed have shown that a plastic increment could be produced on crossing the allotropic range of pure $\mathrm{Bi}_{2} \mathrm{O}_{3},{ }^{9,10} \mathrm{Bi}_{2} \mathrm{O}_{3}-\mathrm{Sm}_{2} \mathrm{O}_{3}$

D. S. Wilkinson—contributing editor

Manuscript No. 189360. Received May 13, 1999; approved April 24, 2000.

Research sponsored by the U.S. Army Research Office (under Contract No. DAAH004-95-1-0629).

Presented in part at the 100th Annual Meeting of the American Ceramic Society, Cincinnati, OH, May 5, 1998 (Creep and Creep-Rupture Poster Session, Paper No. SXVIIP-032-98)

Based in part on the thesis submitted by author JLG for the M.S. degree in Materials Science and Engineering, Northwestern University, 1998.

${ }^{*}$ Member, American Ceramic Society.

Author to whom correspondence should be addressed.

*Now with Tempco Electric Heater Corp., Wood Dale, IL 60191. eutectoids, ${ }^{10,11}$ and the related oxides $\mathrm{Bi}_{2} \mathrm{WO}_{6}$ and $\mathrm{Bi}_{2} \mathrm{MoO}_{6} \cdot{ }^{9,12}$ However, this transformation-mismatch plasticity cannot be called transformation superplasticity, because deformation was observed only in compression and was not repeatable on multiple cycles.

The interest in achieving transformation-mismatch superplasticity in $\mathrm{Bi}_{2} \mathrm{O}_{3}$ is two-fold. First, $\delta-\mathrm{Bi}_{2} \mathrm{O}_{3}$ is an intrinsic fast-ion conductor with applications for solid oxide fuel cells, batteries, sensors, and electrochemical pumps. ${ }^{13,14}$ The complex $\mathrm{Bi}_{2} \mathrm{O}_{3}$ shapes that are necessary for such devices can be achieved by the superplastic forming of unstabilized $\mathrm{Bi}_{2} \mathrm{O}_{3}$, followed by the diffusion of one of the many known stabilizing elements ${ }^{15}$ to retain the $\delta-\mathrm{Bi}_{2} \mathrm{O}_{3}$ phase at room temperature. Second, $\mathrm{Bi}_{2} \mathrm{O}_{3}$ is a good model ceramic for other allotropic ceramics such as $\mathrm{ZrO}_{2}, \mathrm{HfO}_{2}$, or $\mathrm{SiC}$, for which transformation superplasticity is experimentally more difficult, because of the higher transformation temperatures and higher creep strengths in the high-temperature phase.

The present paper reports on the transformation-mismatch plasticity of pure $\mathrm{Bi}_{2} \mathrm{O}_{3}$ that occurs during thermal cycling between two of its allotropic phases. This report differs from the above-reviewed studies on $\mathrm{Bi}_{2} \mathrm{O}_{3}$ in two important ways: first, strain increments are demonstrated over multiple thermal cycles; and second, deformation is conducted in tension (which is a necessary condition to demonstrate superplasticity). Furthermore, the measurements are compared with predictions from existing models of transformation superplasticity.

\section{Experimental Procedures}

Electronic-grade $\mathrm{Bi}_{2} \mathrm{O}_{3}$ powders $(99.9995 \%$ pure, mean particle size of $45 \mu \mathrm{m}$; Metal Specialties Products, Fairfield, CT) were sieved to $-45 \mu \mathrm{m}$, ground with $6 \mathrm{wt} \%$ deionized water for $5 \mathrm{~min}$, and uniaxially pressed at $65 \mathrm{MPa}$ for $90 \mathrm{~s}$ in a rectangular die. The resulting bars were dried, cold isostatically pressed at $275 \mathrm{MPa}$ for $10 \mathrm{~min}$, and sintered in air for $24 \mathrm{~h}$ on an $\mathrm{Al}_{2} \mathrm{O}_{3}$ refractory brick at $700^{\circ} \mathrm{C}$ to the approximate dimensions of $57 \mathrm{~mm} \times 17 \mathrm{~mm} \times 8$ $\mathrm{mm}$ (heating and cooling rates of $5^{\circ} \mathrm{C} / \mathrm{min}$ ). The sintered bars were ground to overall dimensions of $50.1 \mathrm{~mm} \times 16.7 \mathrm{~mm} \times 2.5 \mathrm{~mm}$, and a rectangular gauge section was machined to a length of 16.7 $\mathrm{mm}$, a width of $4.6 \mathrm{~mm}$, and a sharp shoulder radius of $<1 \mathrm{~mm}$. Finally, the tensile specimens were hand-polished with 600 grit $\mathrm{SiC}$ paper to remove any small chips that may have been incurred during machining and ultrasonically cleaned in acetone before testing.

As reported in another publication, ${ }^{8}$ a servo-mechanical testing machine was used in a first series of experiments on six specimens (labeled S1-S6). Before thermal cycling, tensile isothermal creep rates were measured at a temperature of $760^{\circ} \pm 5^{\circ} \mathrm{C}$ in the $\delta-\mathrm{Bi}_{2} \mathrm{O}_{3}$ phase, and these data are used later in the present paper. However, the servo-mechanical machine had difficulties maintaining a constant load during the allotropic transformation; therefore, the thermal cycling results ${ }^{16}$ were considered unreliable and are not reported here.

A creep apparatus that ensured constant-tensile-load conditions was used for nine additional specimens, labeled C1-C9. Specimen elongation was calculated from measurements of the load-train travel outside the hot zone. The specimen temperature was determined with a thermocouple that was located at the center of the gauge length and a few millimeters away from the specimen 
surface, to avoid chemical reaction. After equilibrating at $760^{\circ} \pm$ $5^{\circ} \mathrm{C}$ with minimal stress $(<0.05 \mathrm{MPa})$, the specimens first were deformed in tension under isothermal conditions while maintaining the temperature within $\pm 1^{\circ} \mathrm{C}$, as we have reported elsewhere. ${ }^{8}$ Specimens C1, C4, and C7-C9 subsequently were thermally cycled at a rate of $5^{\circ} \mathrm{C} / \mathrm{min}$ in the temperature range of $600^{\circ}-$ $760^{\circ} \mathrm{C}\left( \pm 5^{\circ} \mathrm{C}\right)$ under constant tensile loads, which produced initial stresses in the range of $0.11-0.55 \mathrm{MPa}$ (see Table I). Except for specimens $\mathrm{C} 1$ and $\mathrm{C} 4$, fracture occurred either during cycling, or just after cycling but before a steady-state isothermal creep rate could be measured. Specimen C1 was further subjected to tensile creep under isothermal and thermal cycling conditions for a second stress level. For all experiments, the specimen stress was calculated using the cross-sectional area that was determined from the instantaneous specimen length, assuming volume conservation and no necking.

The density of each sintered rectangular bar was measured before machining according to ASTM Standard C-373. Also, the density of the head and gauge sections of selected specimens were measured after mechanical testing. The average grain diameter of one sintered specimen with $98 \%$ relative density was determined using the Jeffries planimetric method, ${ }^{17}$ after polishing to $0.3 \mu \mathrm{m}$ alumina and thermal etching in the $\alpha-\mathrm{Bi}_{2} \mathrm{O}_{3}$ phase for $1 \mathrm{~h}$ in air at $700^{\circ} \mathrm{C}$. The mechanically tested specimens were too weak to be polished and were not examined for grain size.

\section{Results}

The average as-sintered $\alpha-\mathrm{Bi}_{2} \mathrm{O}_{3}$ grain size was $13 \mu \mathrm{m}$, and the as-sintered bulk relative densities varied over the range of $97.6 \%$ 99.9\% for all specimens that were subjected to thermal cycling (see Table I). For comparison, relative densities of $85 \%-97 \%$ and grain sizes of $9-17 \mu \mathrm{m}$ were achieved by Johnson et al. ${ }^{9}$ for $\mathrm{Bi}_{2} \mathrm{O}_{3}$ specimens that were hot-pressed at $650^{\circ} \mathrm{C}$ for $45 \mathrm{~min}$ under a stress of $21 \mathrm{MPa}$.

Figure 1(a) shows the measured displacement and temperature history for specimen $\mathrm{C} 4$. On heating under minimal stress, the measured displacement is due to the load-train thermal expansion and specimen phase transformation at $680^{\circ} \mathrm{C}$. During subsequent isothermal creep at $760^{\circ} \mathrm{C}$ and a stress of $0.31 \mathrm{MPa}$, deformation is solely due to specimen creep. Then, on thermal cycling under load, specimen plastic deformation is superimposed to recoverable thermal expansion and contraction of the load train. Finally, during the subsequent isothermal creep, displacement is again due to specimen deformation only. The displacement curve shows discontinuities that correspond to the specimen phase transformations (expansion on heating and contraction on cooling).

Enlarged views of the strain history at the first transformations on cooling and heating under stress are given in Figs. 1(b) and (c), respectively. For cooling, the onset of the phase transformation is well-defined at the last data point before the transformation discontinuity at time $t_{1, \mathrm{c}}$. The end of the transformation, at time $t_{2, \mathrm{c}}$, is located at the corresponding deviation from the best-fit line of the cooling strain curve after the transformation. Then, the transformation time is $\Delta t_{\mathrm{c}}=t_{2, \mathrm{c}}-t_{1, \mathrm{c}}$. A similar procedure has been used for the heating portion of the strain curve, to determine the transformation time on heating $\left(\Delta t_{\mathrm{h}}=t_{2, \mathrm{~h}}-t_{1, \mathrm{~h}}\right)$, as illustrated in Fig. 1(c). The average transformation times for all thermally cycled specimens are $\Delta t_{\mathrm{c}}=138 \pm 124 \mathrm{~s}$ (35 cooling data points) and $\Delta t_{\mathrm{h}}=278 \pm 35 \mathrm{~s}$ (32 heating data points). Transformation temperatures $T_{\mathrm{c}}$ and $T_{\mathrm{h}}$, at the start of the transformations at $t_{1, \mathrm{c}}$ and $t_{1, \mathrm{~h}}$, respectively, are marked with dots on Fig. 1(a) and are reproducible from cycle to cycle. The average values for all specimens are $T_{\mathrm{c}}=648^{\circ} \pm 24^{\circ} \mathrm{C}$ and $T_{\mathrm{h}}=697^{\circ} \pm 7^{\circ} \mathrm{C}$.

Thermal and allotropic expansion and contraction are recoverable over a full thermal cycle; therefore, the strain accumulated from one temperature maximum to the next $\left(\Delta \epsilon_{1}\right)$ in Fig. 1(a) (or from one temperature minimum to the next $\left.\left(\Delta \epsilon_{2}\right)\right)$ is solely due to plastic deformation of the specimen. Figure 2 shows the stress dependence of the average strain accumulated over a complete thermal cycle $\left(\Delta \epsilon_{\mathrm{tot}}\right)$, which is determined as the average of all measured values for $\Delta \epsilon_{1}$ and $\Delta \epsilon_{2}$ for a given specimen, except for the first maximum and minimum, which correspond to the first cooling ramp (at times of 15 and 17 ks, respectively, in Fig. 1(a)) for which a dynamic thermal equilibrium had not been attained in the load train. The standard deviation for each test was used as the error bar in Fig. 2. A point was placed at the origin because no strain increments are expected at zero stress, assuming no thermal ratcheting. The slope of the best-fit line in Fig. 2 is $\Delta \epsilon_{\text {tot }} / \sigma=78$ $\mathrm{GPa}^{-1}$ (which corresponds to a total strain increment of $7.8 \%$ after a full cycle at a stress of $1 \mathrm{MPa}$ ).

Figure 3 shows a photograph of specimen $\mathrm{C} 4$ before and after deformation to fracture to a total strain of $28 \%$, of which $11 \%$ was accumulated during the isothermal creep segments before and after thermal cycling and $17 \%$ during cycling (see Table I). The specimen exhibited partial necking in the gauge length but fractured at the sharp corner at the end of the gauge section, as did most of the specimens used in the present study. A few specimens fractured near the center of the gauge length, as a result of stable crack growth, which was observed visually during cycling after 1-6 cycles. Some of the cracks and the fracture at the head of specimen $\mathrm{C} 4$ in Fig. 3 occurred on rapid cooling after fracture and during extraction of the specimen from the pull-heads.

Table I gives, for selected specimens, the porosity measured after cycling, which increased from the initial porosity by $\sim 1 \%$ for specimens $\mathrm{C} 7$ and $\mathrm{C} 8$ and $\sim 4.6 \%$ for specimen C4. Furthermore, two creep specimens ${ }^{8}$ showed a porosity increase of $\sim 1.5 \%$ after creep deformation at $760^{\circ} \mathrm{C}$ and the transformations that are associated with the initial heating and final cooling with minimal applied stress. Unlike metals, for which porosity is created by cavitation only in the deforming gauge section, no significant difference was observed in the porosity that was created in the head and gauge of the $\mathrm{Bi}_{2} \mathrm{O}_{3}$ specimens, which indicated that the increased porosity is mostly due to thermal cycling (most probably by internal cracking), rather than deformation-induced cavitation.

\section{Discussion}

\section{(1) Transformation-Mismatch Plasticity Strains}

The total plastic strain increment $\Delta \epsilon_{\text {tot }}$ accumulated after each thermal cycle shown in Fig. 2 is the sum of two contributions:

$$
\Delta \epsilon_{\mathrm{tot}}=\Delta \epsilon_{\mathrm{creep}}+\Delta \epsilon_{\mathrm{tp}}
$$

where $\Delta \epsilon_{\text {creep }}$ is the creep strain accumulated during the cycle while the specimen is not undergoing a transformation and $\Delta \epsilon_{\mathrm{tp}}$ is

Table I. Summary of Thermal Cycling Experiments

\begin{tabular}{cccccccc}
\hline Specimen & $\begin{array}{c}\text { Initial } \\
\text { stress } \\
(\mathrm{MPa})\end{array}$ & $\begin{array}{c}\text { Total } \\
\text { number } \\
\text { of cycles }\end{array}$ & $\begin{array}{c}\text { Initial } \\
\text { porosity } \\
(\%)\end{array}$ & $\begin{array}{c}\text { Final } \\
\text { porosity } \\
(\%)\end{array}$ & $\begin{array}{c}\text { Average } \\
\text { strain per } \\
\text { cycle (\%) }\end{array}$ & $\begin{array}{c}\text { Cumulative } \\
\text { cycling strain } \\
(\%)\end{array}$ & $\begin{array}{c}\text { Total } \\
\text { fracture } \\
\text { strain (\%) }\end{array}$ \\
\hline C1 & 0.11 & 6 & 0.1 & & 0.39 & 2.2 & \\
& 0.21 & 10 & & & 1.30 & 7.0 & 12.2 \\
C9 & 0.31 & 4.5 & 0.8 & & 2.67 & 10.1 & 15.2 \\
C4 & 0.31 & 6 & 0.6 & 5.2 & 2.81 & 16.9 & 28.4 \\
C7 & 0.40 & 4.5 & 2.4 & 3.6 & 3.04 & 12.8 & 21.6 \\
C8 & 0.55 & 2.5 & 2.0 & 2.7 & 3.90 & 8.6 & 10.3 \\
\hline
\end{tabular}




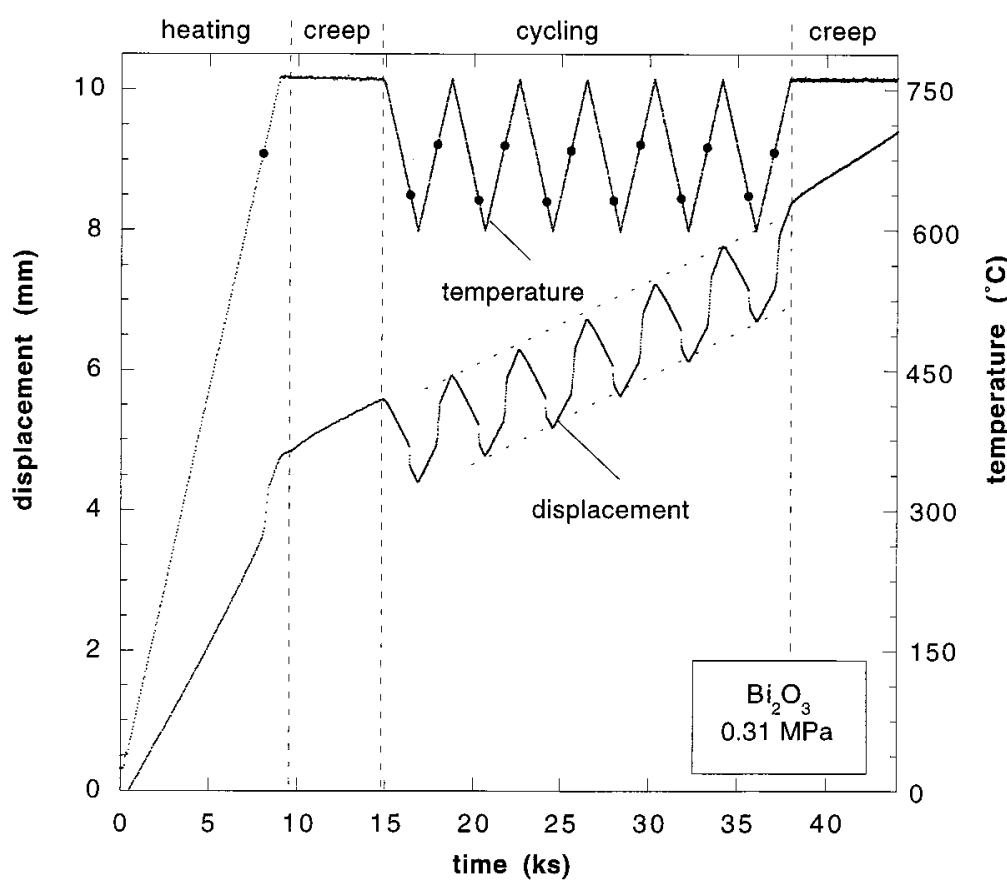

(a)

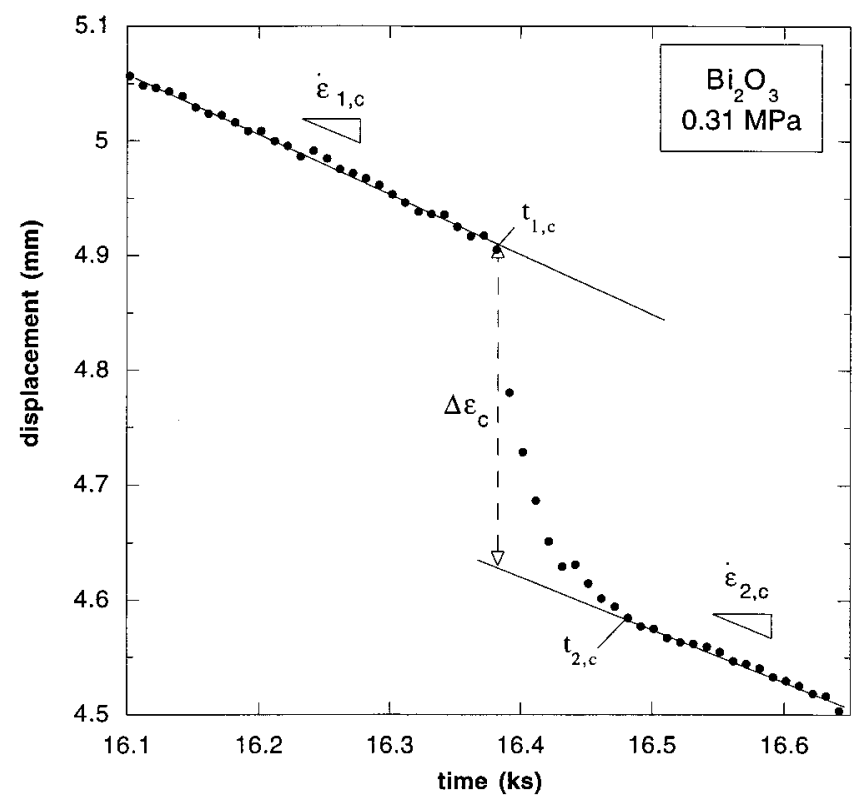

(b)

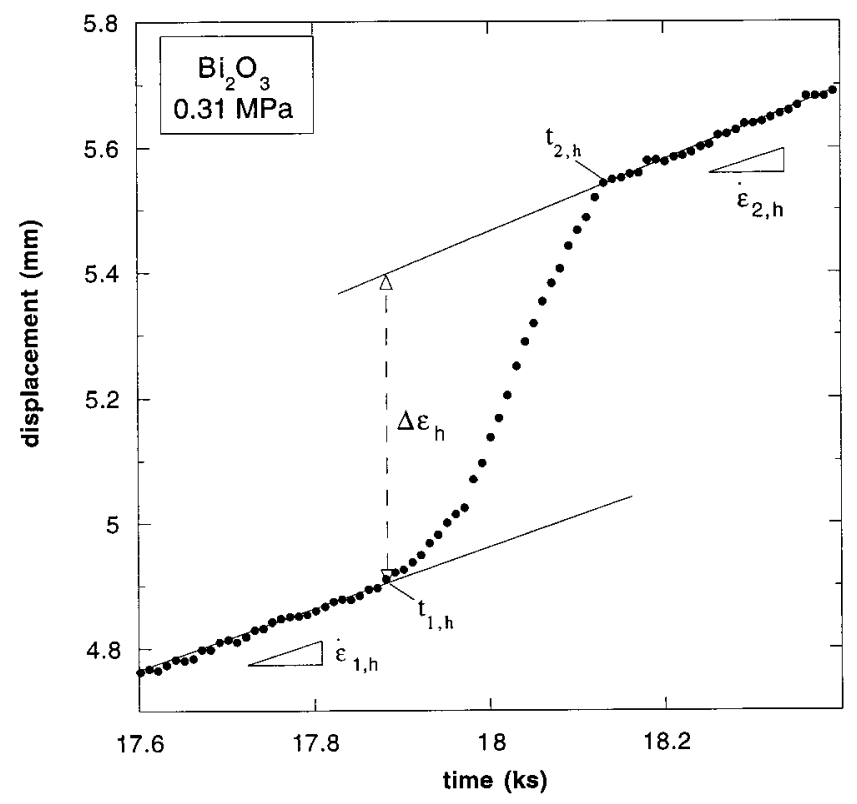

(c)

Fig. 1. (a) Displacement and temperature history of specimen C4, showing heating under minimal stress and creep at $0.31 \mathrm{MPa}$ (thermal cycling creep, preceded and followed by isothermal creep). Temperatures at which the specimen showed an acceleration of strain due to phase transformation are marked with dots. Detailed displacement history of specimen C4 for (b) the first transformation on cooling and (c) the subsequent transformation on heating also is shown.

the plastic strain increment due to transformation plasticity accumulated during both heating and cooling transformations. To compare our results to transformation-superplasticity theory, $\Delta \epsilon_{\mathrm{tp}}$ must be determined first. The first method consists of calculating $\Delta \epsilon_{\text {creep }}$ from the experimentally derived creep constitutive equation and subtracting $\Delta \epsilon_{\text {creep }}$ from the measured value of $\Delta \epsilon_{\text {tot }}$ to find $\Delta \epsilon_{\mathrm{tp}}$ according to Eq. (1). A second method takes advantage of the discontinuities in the strain curve that occur on transformation during the cooling and heating portions of a thermal cycle (see Figs. 1(b) and (c)) to determine $\Delta \epsilon_{\mathrm{tp}}$ directly. Both methods are described in more detail in the following sections.

(A) Creep-Strain Method: The creep strain $\Delta \epsilon_{\text {creep }}$ accumulated outside the transformation range can be calculated, based on the creep constitutive equation of $\delta-\mathrm{Bi}_{2} \mathrm{O}_{3}$, as

$$
\Delta \epsilon_{\text {creep }}=\int_{t_{2, \mathrm{~h}}}^{t_{1, \mathrm{c}}} K \sigma^{n} \exp \left(-\frac{Q}{R T(t)}\right) \mathrm{d} t
$$

where $K$ is the power-law constant, $n$ the stress exponent, $Q$ the activation energy, $R$ the gas constant, and $T(t)$ the temperature history of the specimen in the $\delta$-phase, which is present from $t_{2, \mathrm{~h}}$ to $t_{1, \mathrm{c}}$. Creep in the $\delta$-phase is many orders of magnitude faster than in any of the low-temperature phases; ${ }^{7}$ therefore, creep between $t_{2, \mathrm{c}}$ and $t_{1, \mathrm{~h}}$ when $\delta-\mathrm{Bi}_{2} \mathrm{O}_{3}$ was not present is assumed to be negligible. Here, values of $K=6.0 \times 10^{3} \mathrm{MPa}^{-1 / 3} \cdot \mathrm{s}^{-1}$ and $n=$ 


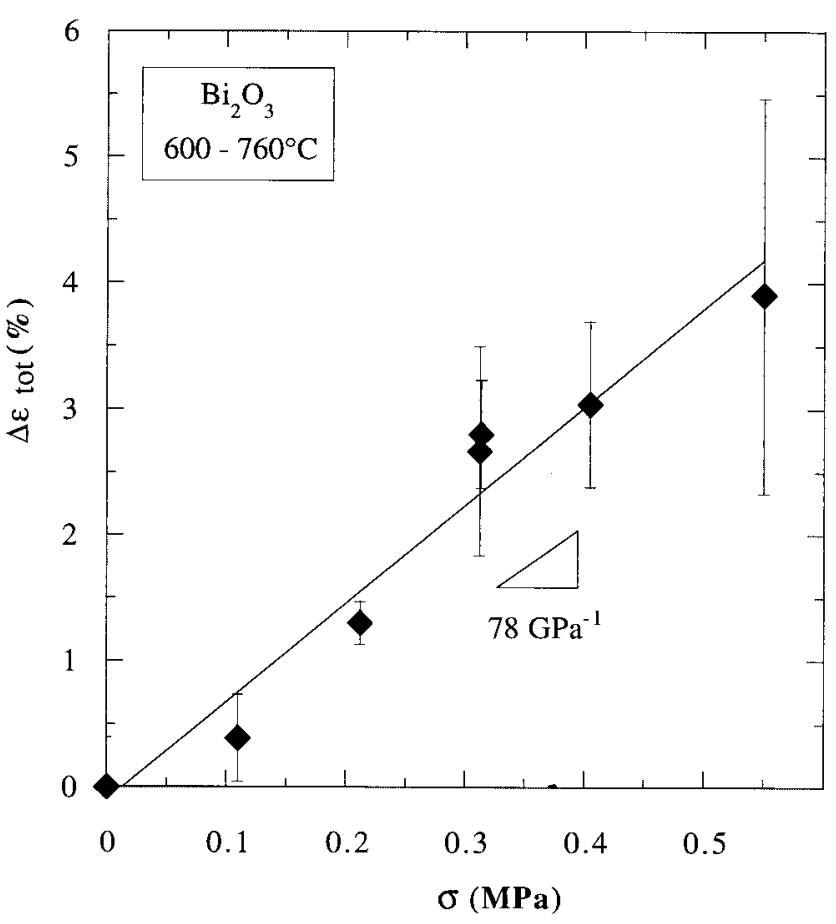

Fig. 2. Average total strain increment, measured after each thermal cycle, as a function of the applied stress (standard deviations are used as error bars).

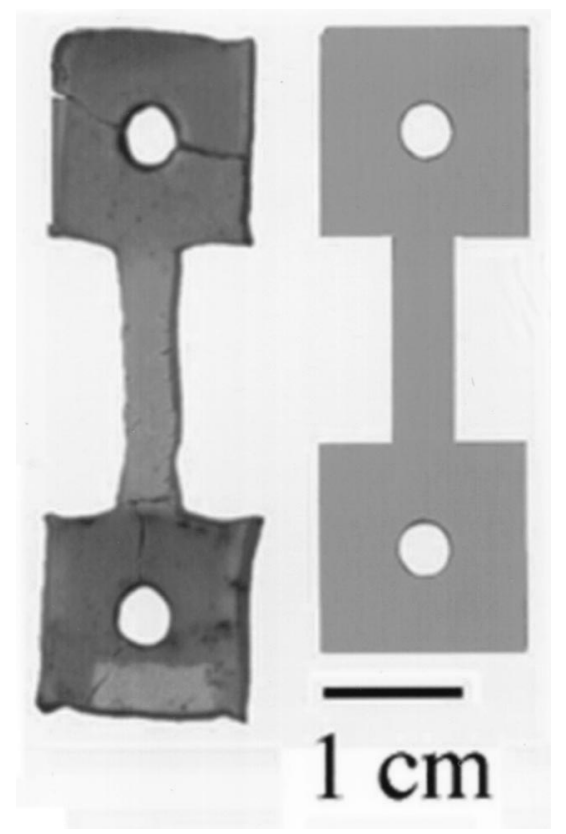

Fig. 3. Photograph of specimen $\mathrm{C} 4$ before testing (right) and after testing (left) (strain to failure of $28 \%$ ).

1.3 have been used; these values were determined from creep data measured at $760^{\circ} \mathrm{C}$ for the stress range of $0.1-0.8 \mathrm{MPa}$ on $\delta-\mathrm{Bi}_{2} \mathrm{O}_{3}$ specimens $\mathrm{C} 1-\mathrm{C} 9$ before and after thermal cycling, as well as specimens S1-S6 before temperature cycling, as we have described in another work. ${ }^{8}$ The average activation energy of $Q=$ $165 \mathrm{~kJ} / \mathrm{mol}$ was used; this value was determined from two experiments in the range of $680^{\circ}-760^{\circ} \mathrm{C}$ for a stress of $0.3 \mathrm{MPa}$, giving $Q_{1}=130 \mathrm{~kJ} / \mathrm{mol}$ and $Q_{2}=200 \mathrm{~kJ} / \mathrm{mol}^{8}{ }^{8}$ That study showed that no significant difference was observed in the measured isothermal creep before and after multiple cycles under load about the phase transformation; therefore, here, we are justified to use the average materials parameters $K, Q$, and $n$ to calculate the creep accumulated during the thermal cycles from Eq. (2). Integration of Eq. (2) was performed numerically, using time intervals of $1.2 \mathrm{~s}$ (which correspond to $0.1^{\circ} \mathrm{C}$ ), based on the experimental temperature profiles, which varied slightly between tests. Using the resulting values of $\Delta \epsilon_{\text {creep }}$, the transformation-plasticity strain increment $\Delta \epsilon_{\mathrm{tp}}$ was determined from Eq. (1) and is shown in Fig. 4 as a function of stress for all thermal cycling experiments (the error bars in Fig. 4 represent extreme values that were calculated using $Q_{1}$ and $Q_{2}$ ).

(B) Strain-Jump Method: For $\mathrm{Bi}_{2} \mathrm{O}_{3}$ with a positive relative mismatch in specific volume $(\Delta V / V)$ on heating, the total uniaxial strain on heating through the phase transformation $\left(\Delta \epsilon_{\mathrm{h}}\right)$ is

$$
\Delta \epsilon_{\mathrm{h}}=\frac{1}{3}\left(\frac{\Delta V}{V}\right)+\Delta \epsilon_{\mathrm{tp}, \mathrm{h}}
$$

where $\Delta \epsilon_{\mathrm{tp}, \mathrm{h}}$ is the transformation plasticity strain accumulated on heating, which is assumed to be completely developed over the transformation time $\Delta t_{\mathrm{h}}$. Similarly, the total uniaxial strain on cooling through the phase transformation $\left(\Delta \epsilon_{\mathrm{c}}\right)$ is

$$
\Delta \epsilon_{\mathrm{c}}=-\frac{1}{3}\left(\frac{\Delta V}{V}\right)+\Delta \epsilon_{\mathrm{tp}, \mathrm{c}}
$$

where the specific volume decrease during the $\mathrm{Bi}_{2} \mathrm{O}_{3}$ phase change on cooling acts to counter the positive transformation plasticity strain increment $\left(\Delta \epsilon_{\mathrm{tp}, \mathrm{c}}\right)$. Thermal expansion strains over the transformation range are neglected in the previous two equations, because of the narrow transformation temperature range.

Then, the total transformation-plasticity strain increment accumulated over one complete thermal cycle $\left(\Delta \epsilon_{\mathrm{tp}}\right)$ is the sum of the transformation plasticity strains accrued during the heating and cooling portions of the cycle:

$$
\Delta \epsilon_{\mathrm{tp}}=\Delta \epsilon_{\mathrm{tp}, \mathrm{c}}+\Delta \epsilon_{\mathrm{tp}, \mathrm{h}}
$$

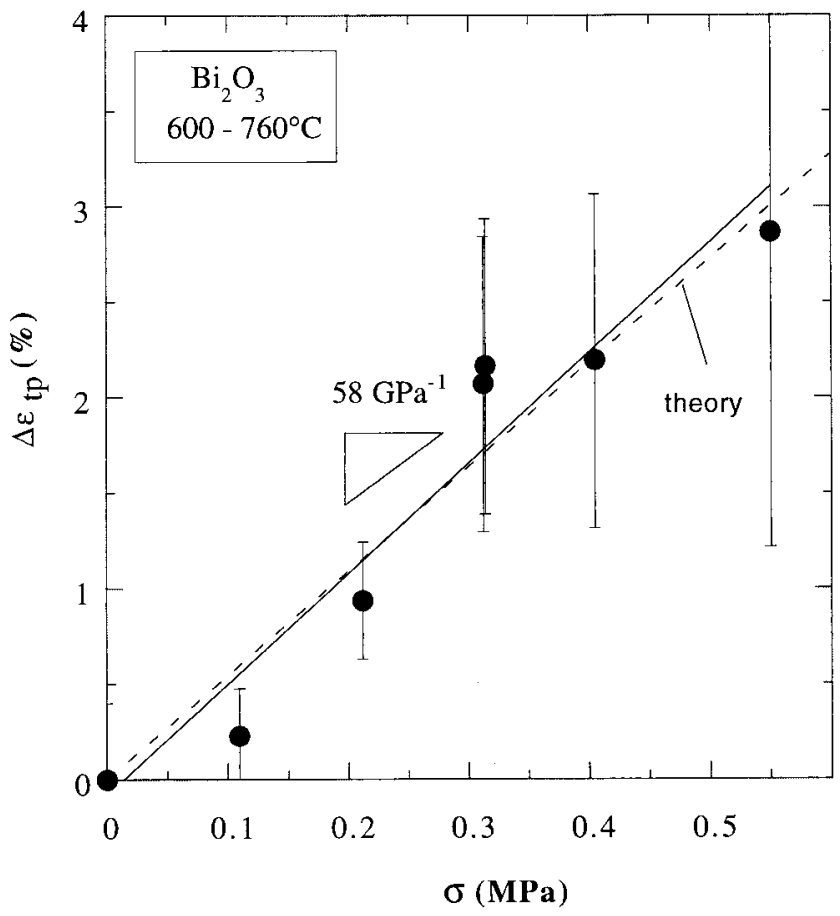

Fig. 4. Dependence on applied stress $(\sigma)$ of the average strain increment due to transformation-mismatch plasticity accumulated after one thermal cycle $\left(\Delta \epsilon_{\mathrm{tp}}\right)$, as calculated by subtracting the creep contribution from the total measured strain increment (Eq. (1)). Error bars are from correction using two activation-energy values. Theoretical line is calculated from Eqs. (7) and (8), using the model by Greenwood and Johnson. ${ }^{22}$ 
Substitution of Eqs. (3) and (4) into Eq. (5) yields

$$
\Delta \epsilon_{\mathrm{tp}}=\Delta \epsilon_{\mathrm{c}}+\Delta \epsilon_{\mathrm{h}}
$$

Thus, experimental determination of $\Delta \epsilon_{\mathrm{c}}$ and $\Delta \epsilon_{\mathrm{h}}$ allows for calculation of the strain increment from transformation plasticity $\left(\Delta \epsilon_{\mathrm{tp}}\right)$. As shown in Fig. 1(b) for the displacement (or strain) curve on cooling, $\Delta \epsilon_{\mathrm{c}}$ is taken at time $t_{1, \mathrm{c}}$ as the strain difference between the two extrapolated lines $\dot{\epsilon}_{1, \mathrm{c}}$ and $\dot{\epsilon}_{2, \mathrm{c}}$. A similar procedure was used for the heating portion of the strain curve to determine $\Delta \epsilon_{\mathrm{h}}$, as illustrated in Fig. 1(c). Figure 5 shows that a linear relationship exists between the applied stress $\sigma$ and the average transformation plasticity strain increment $\Delta \epsilon_{\mathrm{tp}}$, calculated from Eq. (6) with $\Delta \epsilon_{\mathrm{c}}$ and $\Delta \epsilon_{\mathrm{h}}$ determined by the above-described method, using the standard deviation for error bars. Within the substantial experimental error, there is good agreement between the plasticity strains obtained by the creep-strain method (Fig. 4), which is used in most transformation-plasticity studies of metals (see, for example, the work of Dunand and co-workers ${ }^{18-20}$ ), and the strain-jump method (Fig. 5), which is more rarely used in metals. ${ }^{21}$

(C) Comparison with Literature Data: Table II gives a summary of transformation-mismatch plasticity studies on $\mathrm{Bi}_{2} \mathrm{O}_{3}$ and $\mathrm{Bi}_{2} \mathrm{O}_{3}$-based ceramic systems. Comparison with our study is difficult for several reasons. First, all the past research was performed in compression, whereas our study was performed in tension. Experimental errors that are linked to cavitation and cracking in tension and to pore densification, platten friction, and sample barreling in compression are different. Second, except for Smyth et al., ${ }^{11}$ who reported strains accumulated over four cycles for hypereutectoid $\mathrm{Bi}_{2} \mathrm{O}_{3}-8 \% \mathrm{Sm}_{2} \mathrm{O}_{3}$, all other studies failed to obtain any strain after more than a half-cycle (i.e., on initial heating).

In the only existing study that has been performed on pure $\mathrm{Bi}_{2} \mathrm{O}_{3}$, Johnson et al. ${ }^{9}$ reported a transformation-plasticity strain increment per unit stress $\left(\Delta \epsilon_{\mathrm{tp}} / \sigma\right)$ of $190 \mathrm{GPa}^{-1}$ for specimens with a density of $94 \%$ and a grain size of $10 \mu \mathrm{m}$ heated at a rate of $5^{\circ} \mathrm{C} / \mathrm{min}$. The value found in the present study $\left(\Delta \epsilon_{\mathrm{tp}} / \sigma=45-58\right.$ $\mathrm{GPa}^{-1}$, Figs. 4 and 5$)$ is smaller by a factor of $\sim 7$, considering only the heating half-cycle. However, other results by Johnson et

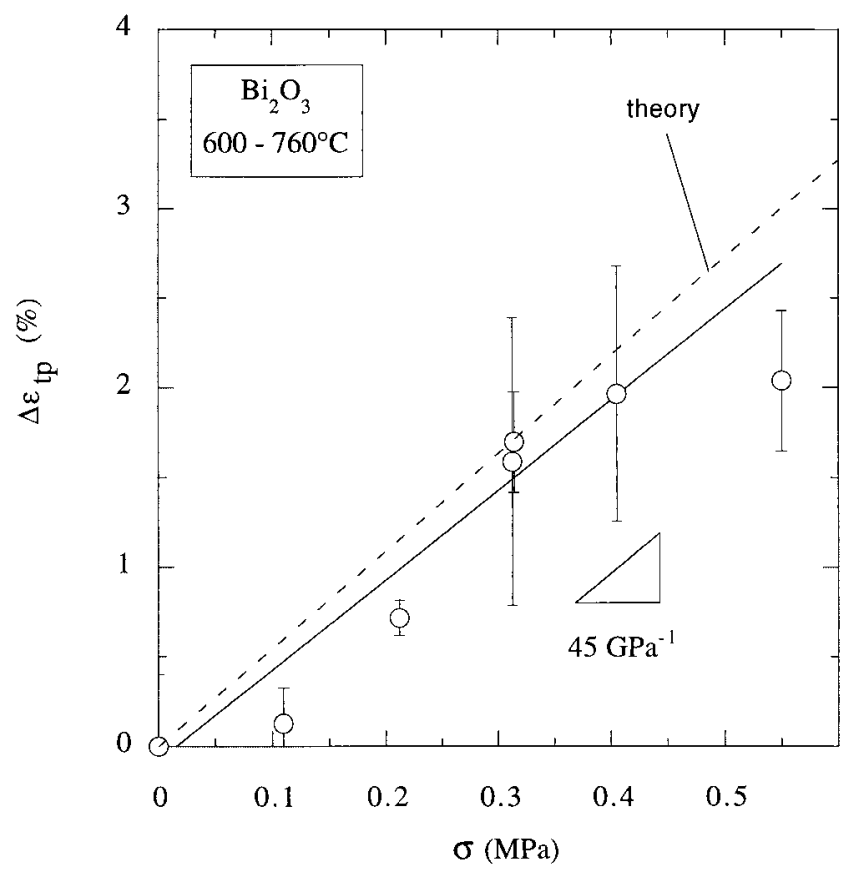

Fig. 5. Dependence on applied stress $(\sigma)$ of the average strain increment due to transformation-mismatch plasticity accumulated after one thermal cycle $\left(\Delta \epsilon_{\mathrm{tp}}\right)$, as determined from strain jumps (Eq. (6)). Standard deviations were used for the error bars. Theoretical line (dashed) is calculated from Eqs. (7) and (8), using the model by Greenwood and Johnson. ${ }^{22}$ $a l .{ }^{9}$ indicate that the transformation strains decrease as the grain size increases (a factor-of-5 difference was observed between specimens with grain sizes of 9 and $17 \mu \mathrm{m}$ ), the heating rate increases (by a factor of 3 , from $2.5^{\circ} \mathrm{C} / \mathrm{min}$ to $14^{\circ} \mathrm{C} / \mathrm{min}$ ), and the porosity increases (by a factor of 2, from $4 \%$ to $9 \%$ ); thus, their $\Delta \epsilon_{\mathrm{tp}} / \sigma$ values span a very wide range $\left(40-360 \mathrm{GPa}^{-1}\right)$.

The two main discrepancies between the results by Johnson et $a l .{ }^{9}$ and our findings are (i) their high transformation-plasticity strain values on initial heating and (ii) their lack of transformation plasticity on cooling and subsequent cycling. The first discrepancy can be explained, in part, by the higher porosity of their specimens, which probably densified during the phase transformation, as well as possibly by large primary creep contributions during and after transformation (they reported decreases of two orders of magnitude in the creep rate of the low-temperature phase after cycling). The lack of subsequent transformation strain was explained by Johnson et al. ${ }^{9}$ by grain growth that occurs in the $\delta$-phase, which decreased the strain that was produced during transformation by a grain-size-sensitive deformation mechanism. However, Vilette and $\mathrm{Kampe}^{7}$ reported that, for $\delta-\mathrm{Bi}_{2} \mathrm{O}_{3}$ with $9 \mu \mathrm{m}$ grains, dislocation creep (which is grain-size independent) was the main deformation mechanism at $750^{\circ} \mathrm{C}$ for stresses as low as $1 \mathrm{MPa}$, well below the maximum stress of $6 \mathrm{MPa}$ used by Johnson et al. ${ }^{9}$ Thus, the reason for the absence of repeatable transformation-plasticity strains in that study is unknown, especially since we were able to measure repeatable, consistent strains increments after each thermal cycle.

(D) Comparison with Model: Greenwood and Johnson ${ }^{22}$ studied pure allotropic metals that were subjected to thermal cycling around the phase transformations and derived an equation for the strain increment that was produced by transformationmismatch plasticity after each crossing of the allotropic temperature:

$$
\Delta \epsilon_{\mathrm{tp}, i}=\frac{2}{3}\left(\frac{\Delta V}{V}\right)\left(\frac{\sigma}{\sigma_{\mathrm{o}, i}}\right)\left(\frac{5 n}{4 n+1}\right)
$$

where the subscript $i$ can be "h" (for heating) or "c" (for cooling), $n$ is the stress exponent of the weakest phase deforming by creep, and $\sigma_{\mathrm{o}}$ is the allotropic internal stress (which is averaged over the transformation time and specimen volume). The data in Figs. 4 and 5 can be fitted with Eq. (7) to an average internal stress of $\sigma_{\mathrm{o}}=$ 1.9-2.4 MPa, assuming that both transformations contribute the same strain (this assumption is discussed later) and using a value of $\Delta V / V=6.9 \%$ for the $\alpha \rightleftarrows \delta$ transformation. ${ }^{6}$ For the stress exponent, we used the dislocation-creep value of $n=3.5$, which was determined from creep data by Vilette and $\mathrm{Kampe}^{7}$ for stresses in the range of $\sim 0.9-2.5 \mathrm{MPa}$ but was valid for stresses as low as $0.3 \mathrm{MPa}^{8}$ Given the high value of the average internal stress, the stress exponent for diffusional creep $-n=1.3$, which is valid over a lower range of stresses $(0.1-0.8 \mathrm{MPa})^{8}$ - cannot be used in Eq. (7). The linear relationship between applied stress and strain increment given by Eq. (7) is valid only when the $\sigma$ value is less than approximately half of the $\sigma_{\mathrm{o}}$ value. ${ }^{19,20,23}$ This condition is fulfilled in our case, because the largest $\sigma$ value is $0.55 \mathrm{MPa}$.

By considering creep relaxation of internal stresses during the transformation, Greenwood and Johnson ${ }^{22}$ showed that the internal stress $\sigma_{\mathrm{o}, i}$ can be expressed as

$$
\sigma_{\mathrm{o}, i}=\left\{\frac{2}{3}\left(\frac{\Delta V}{V}\right)\left(\frac{1}{\Delta t_{i}}\right)\left[\frac{\exp \left(\frac{Q}{R T_{i}}\right)}{K}\right]\right\}^{1 / n}
$$

where $\Delta t_{i}$ and $T_{i}$ are the average duration and temperature of the phase transformations, respectively. Thus, substitution of Eq. (8) into Eq. (7) gives a predictive expression for the transformationplasticity strains per unit stress $\left(\Delta \epsilon_{\mathrm{tp}, i}\right)$, from which the value for a full cycle can be calculated through Eq. (5) and compared with the measured values of $\Delta \epsilon_{\mathrm{tp}} / \sigma=45-58 \mathrm{GPa}^{-1}$. Quantitative evaluation of Eqs. (7) and (8) requires three material parameters that are related to creep of the weakest $\delta$-phase $(K, Q$, and $n)$ and three parameters that are related to the transformations $\left(\Delta t_{i}, T_{i}\right.$, and $\Delta V / V)$. The average power-law creep parameters of $\delta-\mathrm{Bi}_{2} \mathrm{O}_{3}$ can be 
Table II. Summary of Transformation Plasticity Studies on $\mathrm{Bi}_{2} \mathrm{O}_{3}$ and $\mathrm{Bi}_{2} \mathrm{O}_{3}$-Based Ceramics

\begin{tabular}{|c|c|c|c|c|c|c|c|}
\hline Material & $\begin{array}{l}\text { Initial grain } \\
\text { size } \\
(\mu \mathrm{m})\end{array}$ & $\begin{array}{l}\text { Initial } \\
\text { porosity } \\
(\%)\end{array}$ & $\begin{array}{l}\text { Temperature } \\
\text { range } \\
\left({ }^{\circ} \mathrm{C}\right)\end{array}$ & $\begin{array}{l}\text { Stress } \\
\text { range } \\
(\mathrm{MPa})\end{array}$ & $\begin{array}{l}\text { Maximum strain } \\
\text { per cycle, } \\
\Delta \epsilon_{\mathrm{tp}}^{\dagger}\end{array}$ & $\begin{array}{c}\text { Strain per cycle }{ }^{\dagger} \\
\text { and unit stress, } \Delta \epsilon_{\mathrm{tp}} / \sigma \\
\left(\mathrm{GPa}^{-1}\right)\end{array}$ & Reference \\
\hline $\mathrm{Bi}_{2} \mathrm{O}_{3}$ & 13 & $0-2.5$ & $600-760$ & $0.1-0.6$ & 0.03 & 52 & Present study \\
\hline Hypoeutectoid & $9-20$ & 0 & $660-750$ & $0.7-5.9$ & 0.62 & 120 & Smyth et al. ${ }^{11}$ \\
\hline Hypereutectoid & 12 & 0 & $660-750$ & $1.4-5.4$ & 0.55 & 135 & Smyth et al. ${ }^{11}$ \\
\hline $\mathrm{Bi}_{2} \mathrm{WO}_{6}$ & $3-14$ & 6 & $835-935$ & $0.1-0.6$ & 0.75 & $580-900$ & Johnson et al. $^{9}$ and Winger et al. ${ }^{12}$ \\
\hline
\end{tabular}

No strain was measured in the cooling portion of the cycle, except in the present study.

determined from data by Vilette and $\mathrm{Kampe}^{7}$ as $K=7.425 \times 10^{6}$ $\mathrm{MPa}^{-1 / 3} \cdot \mathrm{s}^{-1}, Q=210 \mathrm{~kJ} / \mathrm{mol}$, and $n=3.5$. We have used the measured average transformation times $\Delta t_{\mathrm{c}}$ and $\Delta t_{\mathrm{h}}$ and the average transformation temperatures $T_{\mathrm{c}}$ and $T_{\mathrm{h}}$. Finally, again, for the allotropic volume mismatch, we have used the value $\Delta V / V=$ $6.9 \%$, which has been reported for the $\alpha \rightleftarrows \delta$ transformation by Levin and Roth. ${ }^{6}$ The parameters $\Delta t_{i}, T_{i}$, and $\Delta V / V$ are discussed in more detail in the next sections.

With the above-given materials parameters, Eqs. (7) and (8) give values of $\sigma_{\mathrm{o}, \mathrm{h}}=1.5 \mathrm{MPa}$ and $\Delta \epsilon_{\mathrm{tp}, \mathrm{h}} / \sigma=35 \mathrm{GPa}^{-1}$ for the transformation on heating and $\sigma_{\mathrm{o}, \mathrm{c}}=2.8 \mathrm{MPa}$ and $\Delta \epsilon_{\mathrm{tp}, \mathrm{c}} / \sigma=19$ $\mathrm{GPa}^{-1}$ for the transformation on cooling. Thus, for a full cycle, the strain per cycle is given as $\left(\Delta \epsilon_{\mathrm{tp}, \mathrm{h}}+\Delta \epsilon_{\mathrm{tp}, \mathrm{c}}\right) / \sigma=54 \mathrm{GPa}^{-1}$. This value, which is found using experimentally determined parameters without any adjustable parameters, is consistent with the experimental values $\Delta \epsilon_{\mathrm{tp}} / \sigma=45-58 \mathrm{GPa}^{-1}$ (see Figs. 4 and 5). Similarly, the average internal stresses for both transformations is $\left(\sigma_{\mathrm{o}, \mathrm{c}}+\sigma_{\mathrm{o}, \mathrm{h}}\right) / 2=2.2 \mathrm{MPa}$, which is in good agreement with the value $\sigma_{\mathrm{o}} \stackrel{=}{=} 1.9-2.4 \mathrm{MPa}$ calculated earlier under the rough approximation that the transformations on heating and cooling were the same.

We conclude that, despite the large experimental errors that are present in our measurements, the measured strain increments obtained during thermal cycling of $\mathrm{Bi}_{2} \mathrm{O}_{3}$ can be predicted quantitatively, using the transformation-mismatch plasticity theory developed by Greenwood and Johnson ${ }^{22}$ for pure, creeping materials.

\section{(2) Transformation Temperatures and Times}

Many authors ${ }^{5,6,24-26}$ have reported that monoclinic $\alpha-\mathrm{Bi}_{2} \mathrm{O}_{3}$ transforms to face-centered cubic (fcc) $\delta-\mathrm{Bi}_{2} \mathrm{O}_{3}$ at $730^{\circ} \pm 5^{\circ} \mathrm{C}$ on heating. Levin and Roth $^{6}$ showed that the transformation can follow any of three paths on cooling at a rate of $7^{\circ} \mathrm{C} / \mathrm{min}$, which is comparable to that used in the present study: (i) transformation to stable, monoclinic $\alpha-\mathrm{Bi}_{2} \mathrm{O}_{3}$ at $700^{\circ} \mathrm{C}$; (ii) transformation to metastable, tetragonal $\beta-\mathrm{Bi}_{2} \mathrm{O}_{3}$ at $\sim 650^{\circ} \mathrm{C}$; or (iii) transformation to metastable, body-centered cubic (bcc) $\gamma-\mathrm{Bi}_{2} \mathrm{O}_{3}$ at $\sim 640^{\circ} \mathrm{C}$. The $\delta \rightarrow \alpha$ transformation occurred if the $\delta$-phase was not previously heated above $\sim 745^{\circ} \mathrm{C}$, whereas either the $\delta \rightarrow \beta$ or $\delta \rightarrow \gamma$ transformation could occur for specimens that were heated above $\sim 775^{\circ} \mathrm{C}$. On further cooling, $\gamma-\mathrm{Bi}_{2} \mathrm{O}_{3}$ could be retained to room temperature, whereas $\beta-\mathrm{Bi}_{2} \mathrm{O}_{3}$ transformed to $\alpha-\mathrm{Bi}_{2} \mathrm{O}_{3}$ at $\sim 550^{\circ} \mathrm{C}$. However, if $\beta-\mathrm{Bi}_{2} \mathrm{O}_{3}$ was reheated, the $\beta \rightarrow \delta$ transformation occurred at $\sim 660^{\circ} \mathrm{C}$; for $\gamma-\mathrm{Bi}_{2} \mathrm{O}_{3}, \gamma \rightarrow \alpha$ and $\alpha \rightarrow \delta$ transformations were observed at $625^{\circ}$ and $730^{\circ} \mathrm{C}$, respectively, on heating. Harwig and Gerards ${ }^{5}$ determined similar results, with a few variations: the $\delta \rightarrow \alpha$ transformation was observed at $\sim 640^{\circ} \mathrm{C}$ (instead of $700^{\circ} \mathrm{C}$ ); direct $\gamma \rightarrow \delta$ transformation was observed at $\sim 660^{\circ} \mathrm{C}$ (instead of the $\gamma \rightarrow \alpha \rightarrow \delta$ transformations at $625^{\circ}$ and $730^{\circ} \mathrm{C}$ ); the $\gamma \rightarrow \alpha$ and $\beta \rightarrow \alpha$ cooling transformations could occur over broad temperature ranges of $639^{\circ}-500^{\circ} \mathrm{C}$ and $650^{\circ}-330^{\circ} \mathrm{C}$, respectively. The probability for the $\delta \rightarrow \gamma$ and $\delta \rightarrow \beta$ transformations was approximately the same, with no data for the $\delta \rightarrow \alpha$ transformation.

The above-described literature survey indicates that many transformation paths are possible for our experiments, assuming that the applied stress has no effect on the transformations. Although only the $\alpha \rightarrow \delta$ transformation is expected on initial heating from room temperature to $760^{\circ} \mathrm{C}$, all three transformations $-\delta \rightarrow \alpha, \delta \rightarrow \beta$, or $\delta \rightarrow \gamma-$ are possible on cooling from $760^{\circ} \mathrm{C}$ to $600^{\circ} \mathrm{C}$, with or without subsequent $\beta \rightarrow \alpha$ and $\gamma \rightarrow \alpha$ transformations. On subsequent heating from $600^{\circ} \mathrm{C}$ to $760^{\circ} \mathrm{C}$, the lowtemperature phase is expected to transform back to the $\delta$-phase. Thus, in our case, cycling occurred between the $\delta$-phase and any of the three low-temperature phases (according to $\delta \rightleftarrows \alpha, \beta$, or $\gamma$ ), with no systematic preference for a particular phase and with possible intermediate transformations.

Examination of our data for transformation temperatures on cooling indicates that the average value $T_{\mathrm{c}}=648^{\circ} \pm 24^{\circ} \mathrm{C}$ results from data clustered around two separate temperatures: twenty-six data points with $T_{\mathrm{c}}=638^{\circ} \pm 16^{\circ} \mathrm{C}$ and nine data points with $T_{\mathrm{c}}$ $=683^{\circ} \pm 9^{\circ} \mathrm{C}$. All six specimens first exhibited the lower transformation temperature; four specimens showed the higher transformation temperature after 2-7 cycles. The lower transformation temperature can be assigned to $\delta \rightarrow \beta$ or $\delta \rightarrow \gamma$ transformations, according to the work of Levin and Roth $^{6}$ (and/or to the $\delta \rightarrow \alpha$ transformation, according to Harwig and Gerards ${ }^{5}$ ), whereas the higher transformation temperature can be assigned to the $\delta \rightarrow \alpha$ transformation. ${ }^{6}$ The transformation temperature on heating $\left(T_{\mathrm{h}}=\right.$ $697^{\circ} \pm 7^{\circ} \mathrm{C}$, which, unlike the cooling temperature, showed no systematic variation), does not correspond to any of the values reported by Harwig and Gerards ${ }^{5}$ and Levin and Roth. ${ }^{6}$ However, it is, within error, equal to the transformation temperature that is measured on initial heating without stress $\left(684^{\circ} \pm 6^{\circ} \mathrm{C}\right.$ for five data points) and, thus, can be assigned to the $\alpha \rightarrow \delta$ transformation. The discrepancy between these temperatures $\left(\sim 690^{\circ} \mathrm{C}\right)$ and the literature values $\left(\sim 730^{\circ} \mathrm{C}\right)$ remains unexplained.

The transformation times on cooling were correlated with the transformation temperature: their average value is $\Delta t_{\mathrm{c}}=78 \pm 14 \mathrm{~s}$ for the cycles with the lower transformation temperature and $\Delta t_{\mathrm{c}}=$ $310 \pm 142 \mathrm{~s}$ for those with the higher transformation temperature. As for transformation temperatures, there is no systematic variation for the transformation times on heating $\left(\Delta t_{\mathrm{h}}=278 \pm 35 \mathrm{~s}\right)$. Thus, transformations on both heating and cooling near $690^{\circ} \mathrm{C}$ $(\delta \rightleftarrows \alpha)$ are much longer than the cooling transformation near $640^{\circ} \mathrm{C}(\delta \rightarrow \alpha, \beta$, or $\gamma)$. Two mechanisms can explain this difference. First, the transformation enthalpies for the $\delta \rightarrow \gamma$ and $\delta \rightarrow \beta$ transformations (21 and $22 \mathrm{~kJ} / \mathrm{mol}$, respectively) are less than that for the $\delta \rightarrow \alpha$ transformation $(30 \mathrm{~kJ} / \mathrm{mol}){ }^{5}$ Second, on cooling, the specimens glowed brightly during the exothermic transformation. This phenomenon is typical of recalescence on undercooling and also was observed by Gattow and Schröder, ${ }^{27}$ who reported that the temperature of their $\mathrm{Bi}_{2} \mathrm{O}_{3}$ specimen briefly increased from $647^{\circ} \mathrm{C}$ just before transformation to $712^{\circ} \mathrm{C}$ at the recalescence maximum (our specimens were not in direct contact with the thermocouple; therefore, we did not measure the optically visible temperature jumps). Thus, a specimen that has been undercooled at $\sim 640^{\circ} \mathrm{C}$ and then suddenly heated to the transformation temperature by recalescence will radiate against much-cooler surroundings and transforms more rapidly than a specimen that transforms at $\sim 690^{\circ} \mathrm{C}$ with minimum or no undercooling (or superheating). 


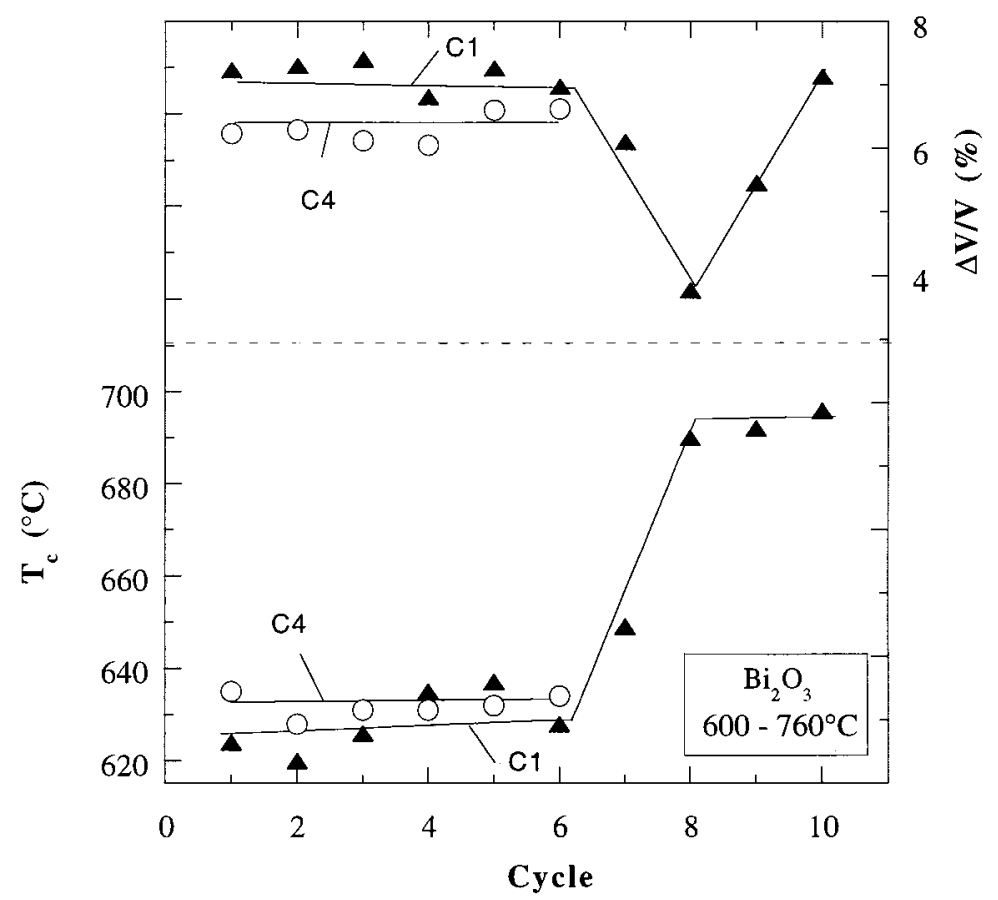

Fig. 6. Temperature for onset of transformation on cooling $\left(T_{\mathrm{c}}\right)$ and calculated allotropic volume mismatch ( $\Delta V / V$, Eq. (10)), as a function of cycle number for tests on specimens $\mathrm{C} 1$ and $\mathrm{C} 4$.

\section{(3) Transformation-Volume Mismatch}

As shown previously, the transformation-plasticity contributions on heating and cooling are different:

$$
\Delta \epsilon_{\mathrm{tp}, \mathrm{c}}=k \Delta \epsilon_{\mathrm{tp}, \mathrm{h}}
$$

where $k=19 / 35=0.55$ in the present case. Substitution of Eqs. (3) and (4) into Eq. (9) gives

$$
\frac{\Delta V}{V}=\frac{3}{k+1}\left(k \Delta \epsilon_{\mathrm{h}}-\Delta \epsilon_{\mathrm{c}}\right)
$$

which allows the determination of the transformation-volume mismatch from measured values of $k, \Delta \epsilon_{\mathrm{h}}$, and $\Delta \epsilon_{\mathrm{c}}$. The average value of the transformation mismatch determined using Eq. (10) with twenty-seven individual measurements of $\Delta \epsilon_{\mathrm{h}}$ and $\Delta \epsilon_{\mathrm{c}}$ for specimens in Table I is $\Delta V / V=6.5 \% \pm 1.0 \%$. This value is in good agreement with the value of $\Delta V / V=6.9 \%$ for the $\delta \rightleftarrows \alpha$ transformation ${ }^{6}$ and is significantly larger than the $\Delta V / V$ values of $2.1 \%$ and $4.5 \%$ for the $\delta \rightleftarrows \beta$ and $\delta \rightleftarrows \gamma$ transformations, respectively. ${ }^{6}$ This result indicates that the $\delta \rightleftarrows \alpha$ transformation was the most prevalent, with possible intermediate phases.

The onset transformation temperature on cooling $\left(T_{\mathrm{c}}\right)$ and the associated allotropic volume mismatch $(\Delta V / V)$ calculated from Eq. (10) are shown in Fig. 6 for tests on specimens C1 and C4. During the first six thermal cycles in both specimens, the values of $T_{\mathrm{c}}$ and $\Delta V / V$ were constant: $\sim 630^{\circ} \mathrm{C}$ and $\sim 6.5 \%$, respectively. The temperature corresponds to any of the $\delta \rightarrow \alpha, \beta$, or $\gamma$ transformations, whereas the allotropic volume mismatch corresponds to the $\delta \rightleftarrows \alpha$ transformation. Specimen $\mathrm{C} 1$, which was subjected to an additional four cycles, showed a transition on cycle 7 and a new equilibrium for cycles $8-10$ at $T_{\mathrm{c}} \approx 680^{\circ} \mathrm{C}$, which is indicative of the $\delta \rightarrow \alpha$ transformation. The value of $\Delta V / V$ varied between $4 \%$ (which was indicative of the $\delta \rightleftarrows \gamma$ transformation), and 7\% (which was indicative of the $\delta \rightleftarrows \alpha$ transformation).

\section{Conclusions}

Bismuth sesquioxide $\left(\mathrm{Bi}_{2} \mathrm{O}_{3}\right)$ specimens were subjected to a constant tensile stress and thermally cycled between the hightemperature, face-centered cubic $\delta$-phase and one or more of the low-temperature phases (monoclinic $\alpha-\mathrm{Bi}_{2} \mathrm{O}_{3}$, tetragonal $\beta-\mathrm{Bi}_{2} \mathrm{O}_{3}$, or body-centered cubic $\gamma-\mathrm{Bi}_{2} \mathrm{O}_{3}$ ). Because of the mismatch in specific volume between these phases, the phase transformations created internal stresses. Their relaxation was biased by the applied stress, which resulted in a macroscopic strain increment after a complete thermal cycle. These strain increments were proportional to the applied stress in the measured range of $0.11-0.55 \mathrm{MPa}$, as predicted from the model for transformation-mismatch plasticity by Greenwood and Johnson. ${ }^{22}$ The measured slope, which was $\sim 52 \mathrm{GPa}^{-1}$ (which corresponds to a strain increment of $5.2 \%$ per cycle at a stress of $1 \mathrm{MPa}$ ), is quantitatively consistent with the theoretical predictions.

Reproducible strain increments were achieved over as many as ten thermal cycles, and a total tensile strain as high as $28 \%$ was accumulated before fracture from both isothermal creep and transformation plasticity. Although many metals have been reported to exhibit tensile strain increments because of transformationmismatch plasticity, the present study is the first documented case for a ceramic. Total tensile elongations of $>100 \%$ on repeated cycling (which are needed to formally claim transformation superplasticity and are observed routinely in metals) should be attainable in $\mathrm{Bi}_{2} \mathrm{O}_{3}$ in the future by inhibiting cracking and using specimens with smoother gauge profiles, thus minimizing stress concentrations near the specimen head.

\section{Acknowledgment}

The authors gratefully acknowledge useful discussions with C. Schuh (Northwestern University).

\section{References}

${ }^{1}$ T. G. Nieh, J. Wadsworth, and O. D. Sherby, Superplasticity in Metals and Ceramics. Cambridge University Press, Cambridge, U.K., 1997.

${ }^{2}$ T. G. Nieh, J. Wadsworth, and F. Wakai, "Recent Advances in Superplastic Ceramics and Ceramic Composites," Int. Mater. Rev., 36, 146-61 (1991).

${ }^{3}$ D. C. Dunand and B. Derby, "Creep and Thermal Cycling"; pp. 191-214 in Fundamentals of Metal-Matrix Composites. Edited by S. Suresh, A. Mortensen, and A. Needleman. Butterworth-Heinemann, Boston, MA, 1993. 
${ }^{4}$ D. C. Dunand, "Transformation Superplasticity in Metals, Alloys and Composites"; pp. 1821-30 in International Conference on Thermomechanical Processing of Steels and Other Materials. TMS, Warrendale, PA, 1997.

${ }^{5}$ H. A. Harwig and A. G. Gerards, "The Polymorphism of Bismuth Sesquioxide," Thermochim. Acta, 28, 121-31 (1979).

${ }^{6}$ E. M. Levin and R. S. Roth, "Polymorphism of Bismuth Sesquioxide, I. Pure $\mathrm{Bi}_{2} \mathrm{O}_{3}$," J. Res. Natl. Bur. Stand., Sect. A, 68A, 189-95 (1964).

${ }^{7}$ A. Vilette and S. L. Kampe, "High-Temperature Plasticity of Cubic Bismuth Oxide," J. Mater. Res., 11, 1433-39 (1996).

${ }^{8}$ J. L. Grabowski and D. C. Dunand, "Tensile Creep Properties of $\delta-\mathrm{Bi}_{2} \mathrm{O}_{3}$," Scr. Mater., in print.

${ }^{9}$ C. A. Johnson, R. C. Bradt, and J. H. Hoke, "Transformational Plasticity in $\mathrm{Bi}_{2} \mathrm{O}_{3}, "$ J. Am. Ceram. Soc., 58 [1-2] 37-40 (1975).

${ }^{10}$ C. A. Johnson, J. R. Smyth, R. C. Bradt, and J. H. Hoke, "Transformational Superplasticity in Pure $\mathrm{Bi}_{2} \mathrm{O}_{3}$ and the $\mathrm{Bi}_{2} \mathrm{O}_{3}-\mathrm{Sm}_{2} \mathrm{O}_{3}$ Eutectoid System"; pp. 443-53 in Deformation of Ceramic Materials. Plenum, New York, 1975.

${ }^{11}$ J. R. Smyth, R. C. Bradt, and J. H. Hoke, "Transformational Superplasticity in the $\mathrm{Bi}_{2} \mathrm{O}_{3}-\mathrm{Sm}_{2} \mathrm{O}_{3}$ Eutectoid System," J. Am. Ceram. Soc., 58 [9-10] 381-84 (1975).

${ }^{12}$ L. A. Winger, R. C. Bradt, and J. H. Hoke, "Transformational Superplasticity of $\mathrm{Bi}_{2} \mathrm{WO}_{6}$ and $\mathrm{Bi}_{2} \mathrm{MoO}_{6}$," J. Am. Ceram. Soc., 63 [5-6] 291-94 (1980).

${ }^{13}$ H. L. Tuller and P. K. Moon, "Fast Ion Conductors: Future Trends," Mater. Sci. Eng., B, 1B, 171-91 (1988).

${ }^{14}$ A. M. Azad, S. Larose, and A. Akbar, "A Review of Bismuth Oxide-Based Solid Electrolytes For Fuel Cells,” J. Mater. Sci., 29, 4135-51 (1994).

${ }^{15}$ E. M. Levin and R. S. Roth, "Polymorphism of Bismuth Sesquioxide. II. Effect of Oxide Additions on the Polymorphism of $\mathrm{Bi}_{2} \mathrm{O}_{3}$," J. Res. Natl. Bur. Stand., Sect. A, 68A, 197-206 (1964).
${ }^{16}$ J. L. Grabowski, "Transformation Superplasticity of $\mathrm{Bi}_{2} \mathrm{O}_{3}$ "; M.S. Thesis. Dept. of Materials Science and Engineering, Northwestern University, Evanston, IL, 1998.

${ }^{17}$ H. E. Boyer and T. L. Gall (eds.), Metals Handbook, Desk Edition. ASM, Metals Park, OH, 1985.

${ }^{18}$ D. C. Dunand and C. M. Bedell, "Transformation-Mismatch Superplasticity in Reinforced and Unreinforced Titanium," Acta Mater., 44, 1063-76 (1996).

${ }^{19}$ P. Zwigl and D. C. Dunand, "Transformation Superplasticity of Zirconium," Metall. Trans. A, 29, 2571-82 (1998).

${ }^{20}$ C. Schuh and D. C. Dunand, "Transformation Superplasticity of Titanium Aluminides," Acta Mater., 46, 5663-75 (1998).

${ }^{21}$ N. Furushiro, H. Kuramoto, Y. Takayama, and S. Hori, "Fundamental Characteristics of the Transformation Superplasticity in a Commercially-Pure Titanium," Trans. Iron Steel Inst. Jpn., 27, 725-29 (1987).

${ }^{22} \mathrm{G}$. W. Greenwood and R. H. Johnson, "Deformation of Metals Under Small Stresses During Phase Transformations," Proc. R. Soc. London, A, 283A, 403-22 (1965).

${ }^{23}$ P. Zwigl and D. C. Dunand, "A Non-Linear Model for Internal Stress Superplasticity," Acta Mater., 45, 5285-94 (1997).

${ }^{24} \mathrm{H}$. A. Harwig, "On the Structure of Bismuth Sesquioxide: The $\alpha, \beta, \gamma$ and

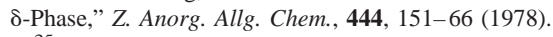

${ }^{25}$ H. A. Harwig and J. W. Weenk, "Phase Relations in Bismuth Sesquioxide," $Z$. Anorg. Allg. Chem., 444, 167-77 (1978).

${ }^{26}$ H. A. Harwig and A. G. Gerards, "Electrical Properties of the $\alpha, \beta, \gamma$ and $\delta$ Phases of Bismuth Sesquioxide," J. Solid State Chem., 26, 265-74 (1978).

${ }^{27}$ G. Gattow and H. Schröder, "Die Kristallstruckture der Hochtemperaturmodifikation von Wismut(III)-Oxid," Z. Anorg. Allg. Chem., 318, 176-89 (1962). 